\title{
Mitochondria as a Favourite Organelle for Invading Viruses
}

\section{Latif Reshi', and Jiann-Ruey Hong ${ }^{1,3 *}$}

${ }^{1}$ Lab of Molecular Virology and Biotechnology, Institute of Biotechnology, National Cheng Kung University, Tainan City 701, Taiwan

${ }^{2}$ Department of Life Sciences, College of Bioscience and Biotechnology, National Cheng Kung University, Tainan City 701, Taiwan

${ }^{3}$ Department of Biotechnology and Bioindustry, National Cheng Kung University, Tainan City 701, Taiwan

\begin{abstract}
The self-destruction of cells infected with viruses undergoes the process of apoptosis generally to restrict infection and the spread of viral progeny. To avoid infection host has evolved interconnected complex defence network that comprises innate and acquired immune response. Mitochondria being considered as powerhouse of a cell is not limited to only energy production, but mitochondria perform various other functions in (disease, apoptosis and host innate immune system) which make them absolutely indispensable to the cell. This makes them a target of almost all the invading pathogens including viruses. Therefore being a multifunctional organelle, the viruses choose mitochondria as a favourite organelle as they can easily take control of the whole cell and make it to promote or block apoptosis as per their need.
\end{abstract}

Keywords: Mitochondria; RNA virus; DNA virus; Pathogens; Apoptosis; Viral proteins

\section{Introduction}

Mitochondria besides acting as a power house of a cell are multifunctional organelles but it is also true that mitochondria are the most suitable target of cells under attack from microorganisms like viruses or ROS produced upon different viral infections although there are also various other targets. Mitochondria perform various other functions which make them absolutely indispensable to the cell, therefore by hijacking the mitochondrial functions upon different viral infection make them easy to take control of the whole cell. Mitochondria has been found to be involved in different signal transduction pathways, play role in process of aging, regulation of different biochemical pathways involved in cellular metabolism programmed cell death, in development, diseases immune response and cell cycle control [1-15]. The mitochondrion contains a single $16 \mathrm{~kb}$ circular DNA genome which encodes 13 polypeptides, 2 ribosomal 12 RNA, 22 tRNA. All of these by-products of mtDNA are essential in electron transport chain for the generation of ATP by the process called oxidative phosphorylation [16]. The ATP generation requires some proteins from both the nuclear genome as well as from mitochondrial Genome. Thus any injury to mitochondria DNA results in serious cell damage. The mtDNA being more suitable to damage is due to lack of protective histones and also it lies in close to electron transport chain which is the main centre of ATP production in mitochondria. Mitochondria possess two well defined compartments: the matrix, surrounded by the inner membrane (IM), and the inter-membrane space, surrounded by the outer membrane $(\mathrm{OM})$. The inner membrane is folded into special structures called as cristae carrying special protein complexes required for electron transport chain and allows free transport of $\mathrm{CO}_{2}, \mathrm{O}_{2}$ and water only. The outer membrane and inner membrane encloses a space called as inter membrane space (IMS) which is fully loaded with apoptotic factors like cyt-c, SMAC/Diablo, endonuclease $G$ which are released when an apoptotic signal is received by mitochondria $(\Delta \psi \mathrm{m})$. The matrix contains different proteins and recyclable molecules required for energy production to be used to perform different functions.

Higher vertebrates have evolved two major mechanisms to control virus infection. One is based on the host's immune response against the virus infection, and the other is biased on cell autonomy, in which cells undergo certain physiological changes upon the onset of infection such as unscheduled activation of the cell cycle by viral proteins. The selfdestruction of virally infected cells through the process of apoptosis generally serves to limit infection and the spread of viral progeny, and therefore accords some degree of protection against infection. Many virus-encoded gene products (proteins) interfere with both the intrinsic and extrinsic apoptotic pathways by interacting directly or indirectly with components of the highly conserved biochemical pathways that regulate PCD or even necrosis (Figure 1). Viruses present a biological puzzle. On the one hand, they block apoptosis by interacting with Bcl-2 anti-apoptotic sensor proteins to prevent premature death of the host cell and so maximize virus progeny from a lytic infection or facilitate a persistent infection. On the other hand, a growing number of viruses appear to actively promote apoptosis by interacting closely with the pro-apoptotic Bcl-2 family sensor proteins upon the completion of a lytic infection and by serving to spread virus progeny to neighbouring cells while evading the host's inflammatory responses. Viruses may perform both functions depending on their need. Recent studies have shown that it is not just the majority of viruses, but also most other plant viruses, that force the cell to undergo the process of apoptosis. However, why the virus forces the host cells to undergo apoptosis is not fully understood and is presently being characterized. Therefore, additional intensive, detailed studies will serve to further elucidate the mechanisms of lytic infection and may provide new drug targets for the treatment of important virus infections.

Apoptosis major form of controlled cell death has a key role in the pathogenesis of many diseases including viral, cancer, inflammation, and neurodegenerative diseases. The process of programmed cell death (PCD) is controlled by a different range of cell signalling pathways originating either from the external environment of a cell (extrinsic) or from within the cell itself (intrinsic) [17]. The common event at the end-point of both the intrinsic and extrinsic pathways is the activation of a set of cysteine proteases (caspase). The extrinsic pathway originates at the plasma membrane following the engagement of a family of cytokine receptors, such as tumour necrosis factor receptor-1 (TNF-R1)

${ }^{*}$ Corresponding author: Dr. Jiann-Ruey Hong, Laboratory of Molecular Virology and Biotechnology, Institute of Biotechnology, National Cheng Kung University, Tainan 701, Taiwan, Tel: 886-6-2003082; Fax: 886-6-2766505; E-mail: jrhong@mail.ncku.edu.tw

Received November 29, 2016; Accepted December 16, 2016; Published December 22, 2016

Citation: Reshi L, Hong JR (2017) Mitochondria as a Favourite Organelle for Invading Viruses. Mol Biol 6: 181. doi: 10.4172/2168-9547.1000181

Copyright: ( 2017 Reshi L, et al. This is an open-access article distributed under the terms of the Creative Commons Attribution License, which permits unrestricted use, distribution, and reproduction in any medium, provided the original author and source are credited. 


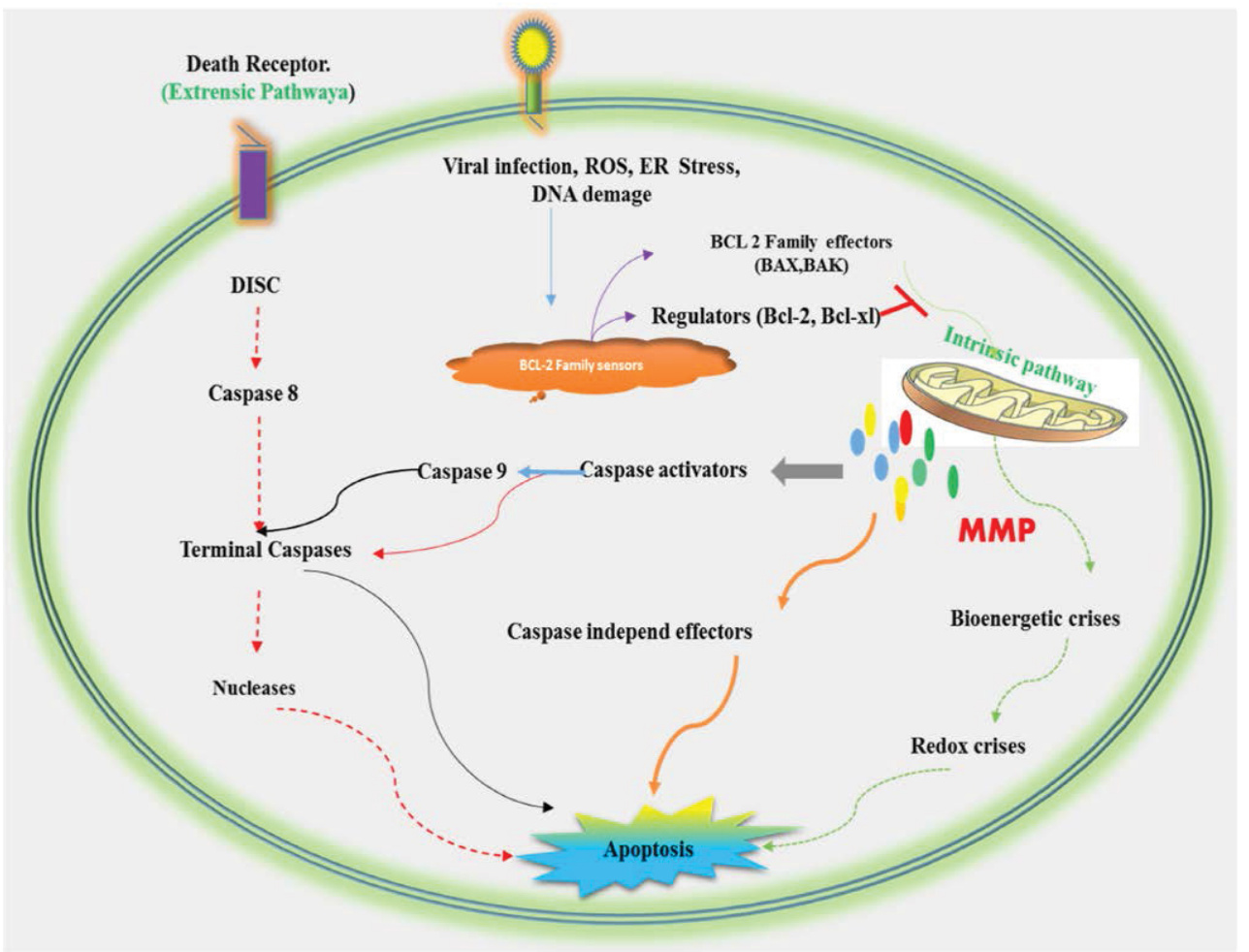

Figure 1: Represents the schematic diagram of extrinsic and intrinsic apoptotic pathways induced by different viruses. The extrinsic pathway originates at the plasma membrane by ligand/receptor binding results in the recruitment of several adapter proteins and proenzymes, which in turn activate caspases (caspase-8 and -10), and finally results in apoptosis and cell death. The intrinsic pathway is triggered by different extracellular or intracellular signals, such as viral proteins oxidative stress, that results in MMP $(\Delta \psi \mathrm{m})$ loss and activation of the initiator caspase-9. Caspase-9, in turn, activates caspase-3, a major effector caspase responsible for the degradation of cellular substrates. The common event at the end-point of both the intrinsic and extrinsic pathways is the activation of a set of cysteine proteases (caspases). ROSreactive oxygen species, ER-endoplasmic reticulum, DISC- death inducing silencing complex.

by their cognate ligands (TNF- $\alpha$ ). Ligand/receptor binding induces the recruitment of several adapter proteins and proenzymes, which in turn activate caspase (caspase- 8 and -10), and finally results in apoptosis and cell death [18]. The intrinsic pathway is triggered by different extracellular or intracellular signals, such as oxidative stress, that results in activation of the initiator caspase-9. Caspase-9, in turn, activates caspase-3, a major effector caspase responsible for the degradation of cellular substrates [19]. Apoptosis may be used by the host both to limit the production of viruses and to disseminate them [20-23]. However, viruses use the apoptosis process to produce sufficient virus progeny or facilitate virus release $[24,25]$. The PCD induced by virus infection has often been defined as typical apoptosis [26-28]. However, recent studies disclosed that non-apoptotic forms of PCD are important for the pathogenesis of certain RNA viruses, including the JC virus, hepatitis C virus, coxsackievirus B3, Enterovirus and dengue virus [21,29]. The mechanism of DNA virus-induced non-apoptotic cell death is not well known. Although not all signals initiating the apoptosis pathway are understood, in many but not all, cases, the tumor suppressor protein p53 is required to propagate the signal to commit suicide [30,31]. The fate of the cell to undergo apoptosis mainly depends on the dynamic balance between the Bcl-2 family sensor proteins, which both promote and inhibit apoptosis (Figure 1) [32]. Members of the Bcl-2 family sensor proteins represent a major key point in the apoptotic pathways. They appear to sit at a node in the apoptotic pathway at a point of integration for stimuli that provoke apoptosis and, in many but not all cases, they appear to influence the activation of caspase family members (proteases), which perform the "execution" phase of apoptosis, by cleaving a number of cellular proteins to bring about the destruction of cellular structures [33].

\section{Mitochondria in normal and apoptotic cells}

Mitochondria are multifunctional organelles covered by outer membrane $(\mathrm{OM})$, and inner membrane and in between lies the inter membrane space. The IM is folded into special structures called as Christie with increases the surface area of inner membrane. The Christie is in turn equipped with protein complexes required for electron transport chain (ETC), ANT and ATP synthase. To function properly, the IM is almost impermeable in physiological conditions there by allowing the respiratory chain to create an electrochemical gradient. The electric potential created is important for maintaining MMP $(\Delta \psi \mathrm{m})$ of IM. The pumping of proton by electron transport chain out of the inner membrane in necessary for activation of ATP synthase which phosphorylates ADP to ATP. The ATP generated on the matrix side of IM is in turn exported by ANT in exchange of ADP. The outer membrane is highly rich in voltage dependent channels (VDAC), which in normal physiological conditions is permeable to solutes of size up to $5000 \mathrm{Da}$. The IMS is chemically equivalent to cytosol in terms of low molecular weight solutes and is rich in special set of proteins. Only 13 subunits of the respiratory chain in the IM are encoded by the small (about 16,500 bp) mitochondrial genome, which resides in the matrix. However rest of almost more than $99 \%$ proteins are encoded by nuclear genome and selectively imported into either of the mitochondrial compartments. The protein composition of the OM, IM, inter membrane space and matrix thus is very unique. 
The MMP $(\Delta \psi \mathrm{m})$ loss results by the imbalance in the membrane potential of both inner as well as outer membranes, which results in arrest of biosynthetic functions as well as bioenergetics crises in a cell. The MMP $(\Delta \psi \mathrm{m})$ loss results in the release of different proapoptotic proteins from IMS like cytochrome c (Cyt c) and Smac/DIABLO, as well as caspase independent death effectors such as apoptosis-inducing factor (AIF) and endonuclease G (EndoG) [34-36].This results in the induction of both caspase independent and caspase dependent cell death [37]. Accidentally induced MMP $(\Delta \psi \mathrm{m})$ contributes to the development of diseases characterized by an excess of cell death, such as ischemia/reperfusion injuries, trauma, toxic/metabolic syndromes as well as chronic neurodegenerative conditions like amyotrophic lateral sclerosis or Alzheimer, Parkinson, and Huntington diseases [38,39]. MMP $(\Delta \psi \mathrm{m})$ is highly regulated process controlled by a different complex network of signaling pathways that involves both endogenous (e.g. pro- and anti-apoptotic Bcl-2 family proteins, p53, kinases, phosphatases, lipid second messengers [40-46], ROS, $\mathrm{Ca}^{2+}$ overload as well as exogenous factors (e.g. viral proteins, toxins, pro-oxidants $[29,47-50]$. As MMP $(\Delta \psi \mathrm{m})$ loss results serious damage to cell and were from the cell has no chances to heal. Therefore in the intrinsic apoptotic cascade, any viral factor that influences MMP $(\Delta \psi \mathrm{m})$ must have a major impact on cell fate, either by inducing or blocking cell death [29].

From the last few years, major efforts and also success have been made to understand of the mechanisms underlying MMP $(\Delta \psi \mathrm{m})$ in disease and health. Recently different models have been proposed and worked in both in vivo and in vitro studies explaining the possible mechanisms underlying the MMP. MMP loss in whatever way results lead to both functional as well as structural collapse of mitochondria that commits the cell to death [51,52]. The question still remains unanswered how these structural modifications of mitochondria might impact on viral infection.

\section{Different models explaining MMP $(\Delta \psi \mathrm{m})$ loss}

The loss of MMP $(\Delta \psi \mathrm{m})$ associated with apoptosis have different effects on both the outer as well as inner membrane which further may or may not result in matrix swelling. The presence of large number of VDAC on OM makes it highly selective and freely preamble to solutes and small metabolites $(5 \mathrm{kDa})$. This cut-off maintains not to lose the matrix from the IMS. The apoptosis associated loss of MMP $(\Delta \psi \mathrm{m})$ has been explained by presenting different models. Usually 4 models have been put forward while carrying the in vitro studies on purified mitochondria.

1st model: The first model explains the permeabilization of IM, when some viral proteins or chemical substances interact with the ANT located on IM which results in osmatic matrix swelling and OM rupture (Figure 3). The OM rapture because the surface area of the IM with its folded cristae exceeds that of the OM (Figure 3). Many well-known MMP $(\Delta \psi \mathrm{m})$ regulators, like Bak, Bax, Bcl-xl, Bcl-2 and cyclophilin D (mitochondrial target of cyclosporine A,), interact with the ANT located on mitochondrial inner membrane [53-55]. Recent studies has discovered various viral proteins with apoptosis inducing and apoptosis-inhibitory (pUL37x from cytomegalovirus) (Vpr from

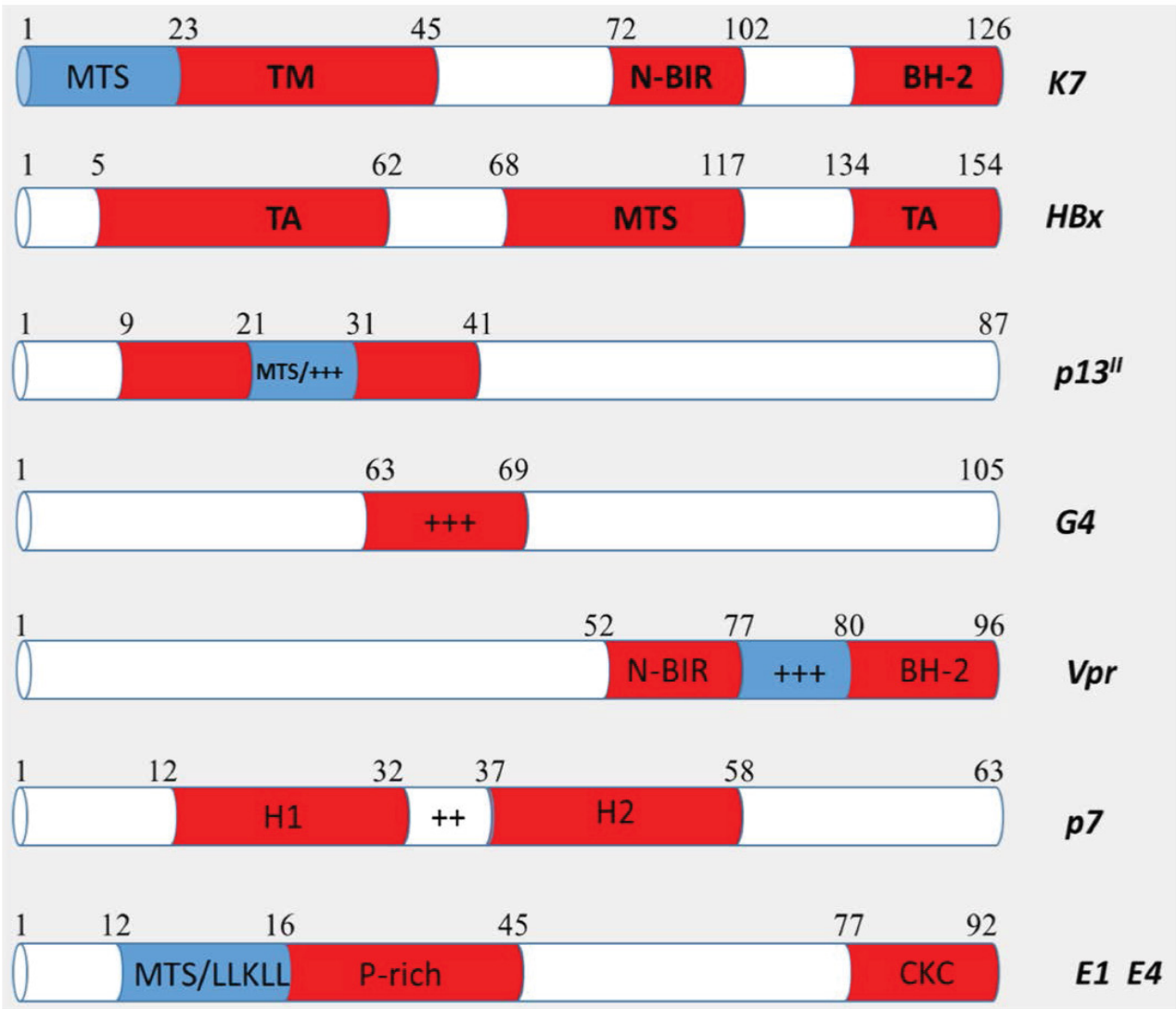

Figure 2: Showing the functional domains identifies in different viral proteins acting through mechanisms different from that of vBcl-2. TM, transmembrane domain; MTS, mitochondrial targeting signal; LLKLL, cut leucine-rich region; TA, transactivation domain; BH2, BCL-2 homology region; $N$-BIR, baculovirus internal repeat-like domain; CKC, domain required to collapse the keratin network, which also contains sequences directing multimerization. +++, positively charged amphipathic -helix; $H 1, H 2$, -helical regions; The MTS/LLKLL sequence of HPV E1^E4 protein serves both for keratin binding and mitochondrial targeting . 


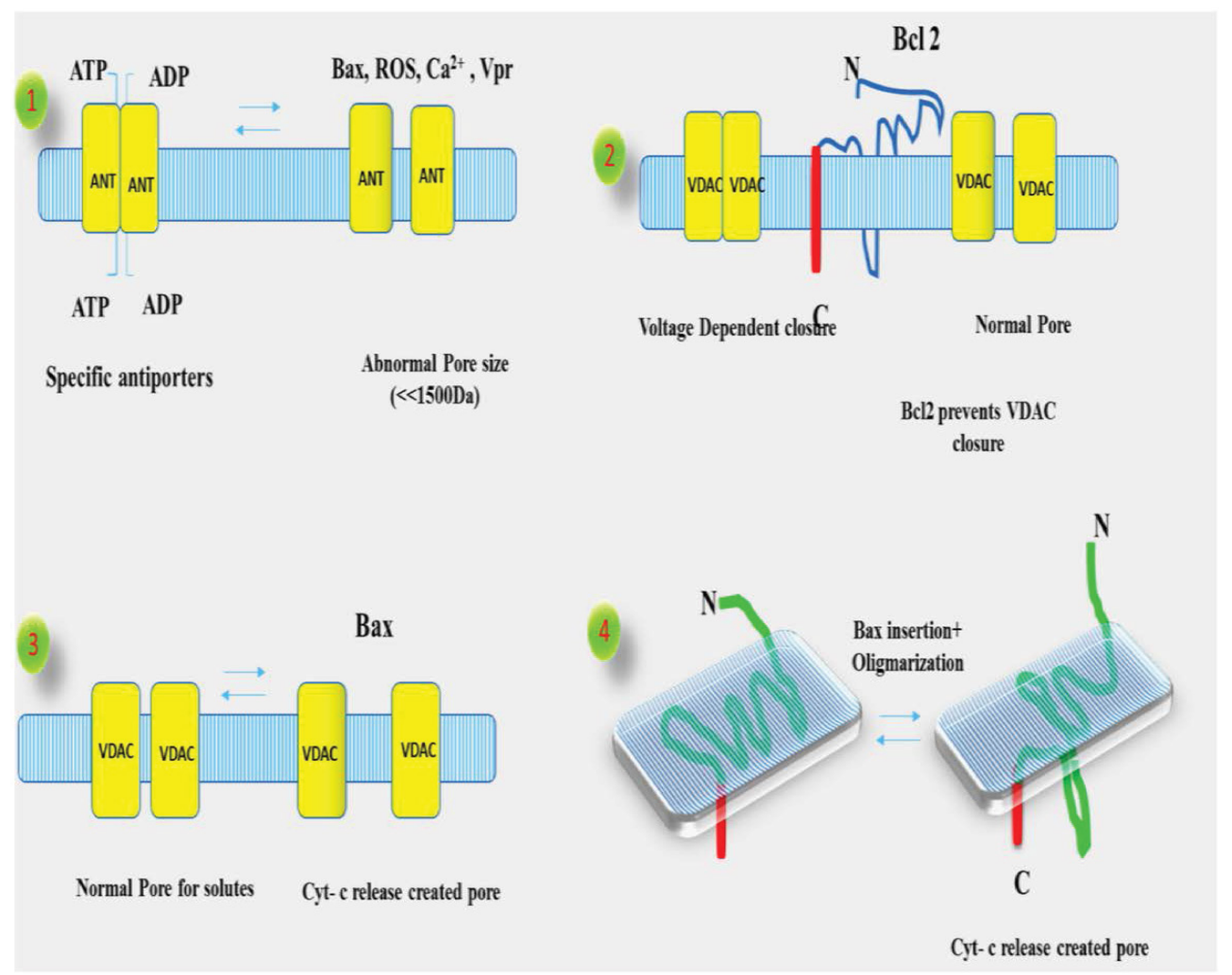

Figure 3: Schatemic diagram explaining the different possible mechanisms of MMP $(\Delta \psi \mathrm{m})$ loss due to permebilization of both outer as well as inner membrane. 1, Normal adenine nucleotide translocator (ANT) functions as a vital ATP/ADP-specific antiporter or in case of MMP ( $\triangle \psi m$ ) loss can act as a lethal nonspecific pore. Pore formation is aided by interaction with cyclophilin $\mathrm{D}(\mathrm{CypD})$. 2, The inhibition of voltage dependent closure of VDAC is carried by anti-apoptotic protein Bcl-2 which otherwise will be destructive. 3, The voltage-dependent anion channel (VDAC) may be converted into a cytochrome-c-release permanent pore. 4, Oligemerization of Bax can form a nonspecific pore without requiring interactions with different mitochondrial membrane proteins.

HIV-1) activity that also interact particularly with VDAC and ANT $[56,57]$.

2nd model: The second model explains the pore formation by VDAC on OM without affecting the inner membrane (Table 1,2). This MMP $(\Delta \psi \mathrm{m})$ loss has further been found to be enhanced by Bax and inhibited by Bcl-2 in vitro. The formation of pore on the outer membrane by the interaction of Bax with VDAC when inhibited by Koenig's polyanion, (VDAC inhibitor), results that it is VDAC, not Bax, which plays the actual role of MMP $(\Delta \psi \mathrm{m})$ loss on the outer mitochondrial membrane.

3rd model: The third model explains that the oligomerization of Bax on mitochondrial membrane when Bax is translocating from cytosol to mitochondrial membrane results in the formation protein translocation channel which is independent of VDAC. Thus the Bax and VDAC act independently depends upon the apoptotic inducing signal (Figure 3,4) [58,59].

4th model: In the fourth model, the VDAC regulates MMP $(\Delta \psi \mathrm{m})$ through yet another mechanism related to its functional and physical contact with the ANT (Figures 3 and 4). An apoptosis-related increase in DYm (IM) would transfer charges to the OM, thereby resulting in closure of the VDAC (which closes when voltage increases) [60]. The Bcl-2 may play its role by acting as an ionophore (Ion permeable and protein impermeable) to maintain the electrical mitochondrial membrane potential across the outer membrane. Therefore $\mathrm{Bcl}-2$ indirectly plays its role by exchange of ATP/ADP (VDAC- and ANTdependent continuous exchange of ATP/ADP )across mitochondrial membrane which results in avoiding the interspace matrix swelling which results as a consequence of instability in VDAC/ANT [60,61].

\section{Role of mitochondria in host immune response}

The viral entry into the host cell activates signaling pathways, leading to the production of IFN's, inflammatory cytokines and chemokine's which limit or eliminate the invading virus. The host cell uses pattern recognition receptors (PRR's) to detect viral foreign nucleic acids. There are three types of PPR's-TLR's, RIG 1 and nucleotide oligomerization like receptor(NOD) TLR-3 are present in all immune cells and recognize dsRNA. The RIG-1 is special receptors with $c$ terminal domain having helicase activity which is ATP dependent, whereas the $\mathrm{N}$ terminal domain of RIG-1 has two caspase activation and recruitment domains (CARDs). The conformational changes of RIG 1 expose its CARD domains to bind and activate downstream effectors leading to the formation of enhance some triggering NF- $\kappa B$ production [62].

Recently another protein which functions downstream of RIG1 with CARD domain have been identified. This proteins are known by different names like mitochondrial anti-viral signaling protein (MAVS), virus-induced signaling adaptor (VISA), IFN- promoter stimulator 1 (IPS-1) and CARD adaptor inducing IFN- (CARDIF) [6366]. Research indicates that the MAVS has an important role in raising the antiviral defences in the cell. The in vivo knockout studies with MAVS -/- deficient mice has shown compromised immune response against viruses, though they don't show any developmental abnormality 


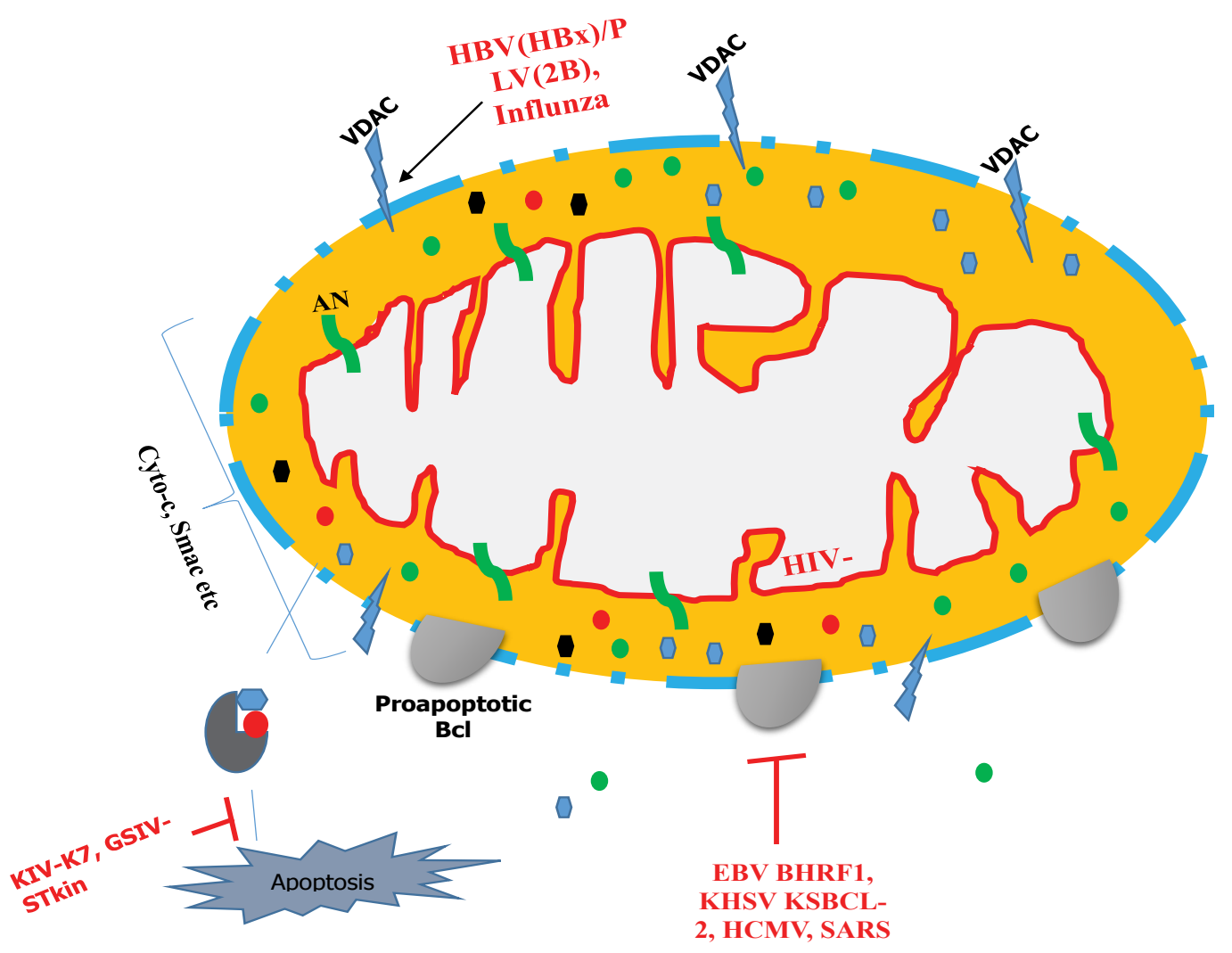

Figure 4: Showing interaction of different viral proteins with mitochondria. The apoptotic signal received by mitochondria results in MMP ( $\Delta \psi \mathrm{m})$ loss by imbalance in BCL-2 family protein which ultimately activates downstream apoptotic signals.

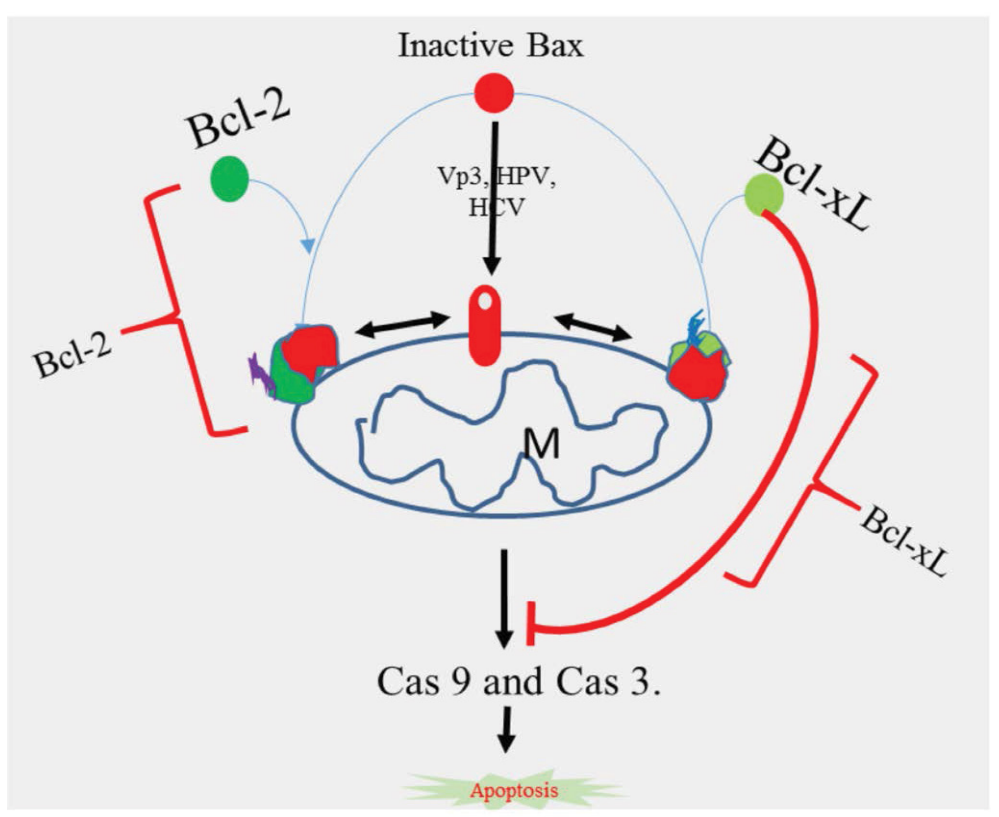

Figure 5: Inactivation of Bax can be directly converted into active form by interacting with proteins with $\mathrm{BH} 3$ domains. The activated Bax undergoes oligomerization on mitochondrial membrane and results in pore formation that ultimately leads to MMP $(\Delta \psi \mathrm{m})$ loss. However the interaction of Bax with anti-apoptotic proteins Bcl-2 and Bcl-x drives the relocalization of Bax exposing the $\mathrm{N}$ terminal domain that unable its insertion into mitochondrial outer membrane. Recent studies have shown that Bax can be activated by different viral proteins other than containing BH3 domains. However the complete mechanisms are not well understood. Example like (GSIV -ST-kinase) 


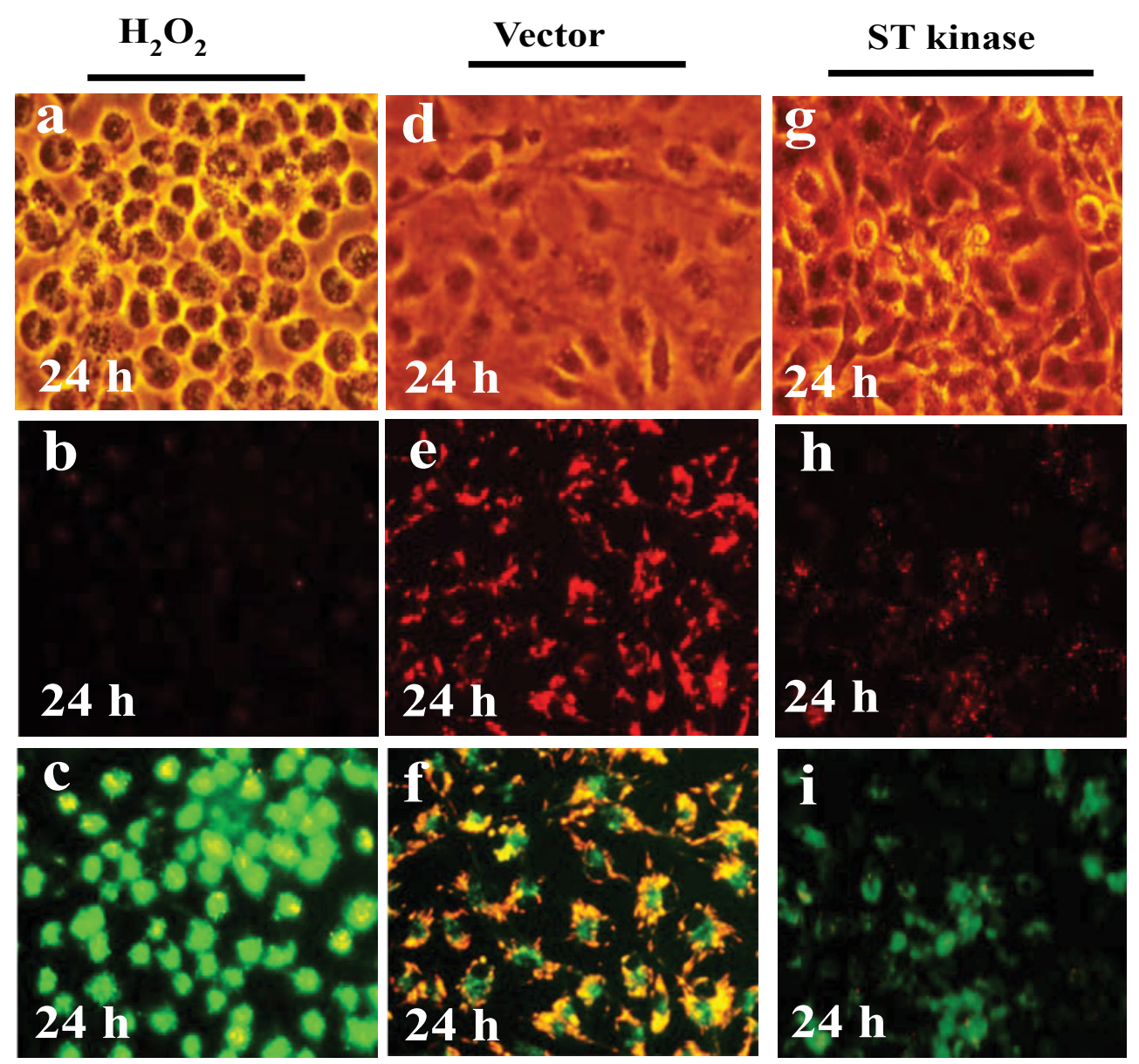

Figure 6: GSIV ST-kinase induced MMP loss by JC1 lyophilic dye in grouper fish GF-1 cells at 24 hpt, upon transfection by ST kinase ( $\mathrm{g}$-i) and control vectors (d-f). Hydrogen peroxide treatment $(\mathrm{a}-\mathrm{c})$ is as a positive control. The red color indicates the healthy mitochondria whereas the increase in green fluorescence indicates the MMP loss.

[67]. Overexpression of MAVS leads to activation of NF- $\kappa B$ and IRF-3, leading to the induction of type I interferon response. In the absence of MAVS, this effect is abrogated [68] indicating the specific role of MAVS in inducing antiviral response. Although the present studies about the proteins acting downstream of MAVS to induce interferon production has not yet given any solid clue. The C-terminal Trans membrane domain of MAVS has been found vital in targeting the proteins to the mitochondrial outer membrane instead of protein rich region [68]. Further domain studies have revealed that the $C$ terminal Trans membrane domain of MAVS share similarity with the $\mathrm{cterminal}$ tails of various proteins located on the mitochondrial outer membrane like Bcl$\mathrm{xl}$ and $\mathrm{Bcl}-2$. Therefore the ability of viruses to hijack the localization of MAVS to different cellular organelles instead of their target organelles or affecting their cleavage from mitochondria ultimately effects the interferon production which viruses use to protect from host immune response.

\section{Viral proteins targeting mitochondria}

Many virus-encoded gene products (proteins) interfere with both the intrinsic and extrinsic apoptotic pathways by interacting directly or indirectly with components of the highly conserved biochemical pathways that regulate apoptosis or even necrosis [32]. Viruses present a biological puzzle. On the one hand, they block apoptosis by interacting with Bcl-2 anti-apoptotic sensor proteins to prevent premature death of the host cell and so maximize virus progeny from a lytic infection or facilitate a persistent infection. On the other hand, a growing number of viruses appear to actively promote apoptosis by interacting closely with the pro-apoptotic Bcl-2 family sensor proteins upon the completion of a lytic infection and by serving to spread virus progeny to neighbouring cells while evading the host's inflammatory responses. Viruses may perform both functions depending on their need. Recent studies have shown that it is not just the majority of aquatic viruses, but also most other viruses, that force the cell to undergo the process of apoptosis. Obviously, viruses target the central parts of the proapoptotic signal transduction and execution machineries. Examples of proteins that subvert pro-apoptotic signals include viral proteins that block tumour necrosis factor (TNF) and its signals [69] viral proteins that inhibit ds-PKR, a protein kinase that is activated by ds-RNA (and which can initiate apoptosis in virus-infected cells) [70] viral proteins that inhibit p53 (a transcription factor that is often rate-limiting for DNA damageinduced apoptosis) [71,72] and viral proteins that inhibit caspase $[73,74]$. In addition, viral proteins are often acting on mitochondrial receptors and membranes to inhibit or induce MMP $(\Delta \psi \mathrm{m})$ and this is the focus of the present paper (Tables 1 and 2).

Many viral proteins that alter mitochondrial ion permeability and/ or membrane potential have been identified. Most prominent of these are discussed below:

1. Poliovirus (PLV) infection causes acute disease called as paralytic poliomyelitis which results in flaccid paralysis due 


\begin{tabular}{|c|c|c|c|c|}
\hline Virus & Protein & Intracellular Localization & $\begin{array}{c}\text { Effect on mitochondrial } \\
\text { morphology }\end{array}$ & References \\
\hline HBV & $\mathrm{x}$ & $\mathrm{M}, \mathrm{N}$ & Yes & $98-101$ \\
\hline HIV & Vpr & $\mathrm{M}, \mathrm{N}$ & Yes & 39 \\
\hline IAV & PB1-F2 & $\mathrm{M}, \mathrm{N}$ & Yes & 93 \\
\hline HTLV-1 & P13 II & $\mathrm{M}, \mathrm{N}$ & Yes & 40 \\
\hline BLV & G4 & $\ldots \ldots$ & Yes & 124 \\
\hline AVE & VP3. 2C & $\mathrm{M}$ & Yes & 112,113 \\
\hline WDSV & Orf C & $\mathrm{M}, \mathrm{C}$ & Yes & 76 \\
\hline HPV type 16 & $\mathrm{E} 1^{\wedge} \mathrm{E} 4$ & M & & 79,81 \\
\hline NNV & B2 & $\mathrm{M}, \mathrm{C}$ & Yes & 123 \\
\hline GSIV & ST-Kinase & $\mathrm{C}$ & Yes & 122 \\
\hline
\end{tabular}

Table 1: Proapoptotic viral proteins acting on the mitochondria.

\begin{tabular}{|l|c|c|c|c|}
\hline Virus & Protein & Intracellular Localization & Protects Cell from \\
\hline KSHV & K7 or vIAP & M, ER, PM & TG, TNF-a, anti Fas \\
\hline HCV & NS2 & ER (M with CIDE-B) & CIDE-B \\
\hline Myxoma & M11L & M & STS, anti-Fas, PPIX \\
\hline Vaccinia & FIL & M & STS, anti-Fas \\
\hline CMV & vMIA & M & Oxidants, anti-Fas, Bax, tBid, TN,TG, STS, BFA, NFX, CPX, HCQ & $117-121$. \\
\hline
\end{tabular}

Table 2: Antiapoptotic viral proteins acting on the mitochondria.

to caspase dependent apoptosis of motor neurons [75]. The polio virus encoded viroprotein $2 \mathrm{~B}$ induces a perinuclear redistribution of mitochondria and ultimately alters their morphology resulting in MMP $(\Delta \psi \mathrm{m})$ loss [76] in a similar fashion as by HBx protein of hepatitis B virus.

2. The overexpression of Orf C of WDSV, a retrovirus causing benign tumors in fish characterized by seasonal regression $[77,78]$. Cause similar perinuclear clustering of mitochondria and MMP $(\Delta \psi \mathrm{m})$ loss followed by cytochrome $\mathrm{c}$ release and other apoptosis inducing factors.

3. The E1 and E4 are two early genes encoded by spliced mRNAs of HPV virus genome. The in vitro studies carried on mature human keratinocytes have shown that E1 E4 binds and collapses cytokeratin network of cells [79]. Then makes a way towards mitochondria by special $\mathrm{N}$ terminal Lucien rich mitochondrial localization signal were it detaches mitochondria and get them aggregated around the nucleus. The detached mitochondria undergo morphological change and results in MMP $(\Delta \psi \mathrm{m})$ loss and apoptosis. Several other proteins like E6 and E7 play a role in prevention of p53 induced apoptosis [80-83].

4. The anti-apoptotic core protein of HCV inhibits the DCA induced mitochondrial apoptosis. The core protein inhibits DCA induced mitochondrial apoptosis by inhibiting Bcl-2 family proteins. The viral core protein decreases the expression of Bax and increases the expression of Bcl-xl anti-apoptotic protein but there occurs no overall change in Bax in between cytosol and mitochondria. The increase in Bcl-xL expression suppress the cytochrome $c$ release from mitochondria and inhibits DCA induced apoptosis. Another research has shown TNF alpha induced apoptosis is blocked by HCV core protein but sensitizes cells to Fas mediated apoptosis $[84,85]$.

5. The in vitro studies of protein $\mathrm{M}$ and protein $\mathrm{P}$ of VSV rhabdovirus causes mitochondrial apoptotic pathways. The virus usually causes apoptosis of neurons [86]. The M protein causes the modulation of the BCL-2 family proteins whereas the exact mitochondrial apoptotic pathway in case of protein $\mathrm{P}$ is still unknown [87-90].
6. The protein PB1-F2 encoded by the genome of Influenza A virus is a death inducing gene. It mainly induces mitochondrial mediated cell death [91]. It has a C-terminal mitochondria localization signal, which is conserved in the influenza family [92,93]. PB1-F2 while localizing to mitochondria usually interacts directly with VDAC1 and ANT3 figure 4 [94]. This interaction involves both $\mathrm{OM}$ and IM of mitchondria and ultimately leads the release of apoptotic protein from IMS thereby causing cell death Therefore protein PB1-F2 distorts the mitochondrial morphology leading to MML loss and cell death.

7. Viruses altering intracellular distribution of mitochondria so that the host cell mitochondria is subservient to the needs of the virus by $\mathrm{HBV}$

Hepatitis $B$ virus $x$ protein $(\mathrm{HBx})$ is a protein essential for viral replication and shows oncogenic properties in animal models [95]. The overexpression $\mathrm{HBx}$ sensitizes hepatocytes to apoptosis induced by different stimuli such TNF- $\alpha$ and TRAIL [95]. The overexpression studies of protein $\mathrm{HB} \times \mathrm{x}$ has shown that protein causes apoptosis by perinuclear mitochondrial distribution coupled with MMP $(\Delta \psi \mathrm{m})$ loss. Mutant Studies of HBx has revealed that hydrophobic residues (MTS) are important for mitochondrial localization, MMP $(\Delta \psi \mathrm{m})$ loss and cell death [96,97]. Moreover, PT inhibitors, antioxidants and the anti-apoptotic proteins $\mathrm{Bcl}-2$ and $\mathrm{Bcl}-\mathrm{xL}$ are able to protect $\mathrm{HBx}$ expressing cells from death. HBx reportedly interacts with at least two mitochondrial proteins, namely heat shock protein 60(HSP60) [98] and theVDACisoformVDAC3 [97] but still the exact mechanism of interaction is not clearly understood. It is unknown whether these interactions occur simultaneously. The apoptosis induced by HBx protein Viz. mitochondrial dysfunction and changes in mitochondrial morphology has been found to play a major role in chronic liver disease and carcinogenesis [99-102].

8. The vMIA (Viral mitochondrial inhibitor of apoptosis) protein of cytomegalovirus (HCMV) is an anti-apoptotic protein which blocks the mitochondrial mediated cell death [103]. The protein has $\mathrm{N}$ terminal mitochondrial localization signal and $\mathrm{C}$ terminal 
anti-apoptotic domain which recruits Bax to mitochondria and inhibits apoptotic process induced by MMP $(\Delta \psi \mathrm{m})$ loss [104]. It localizes to mitochondria and interacts with ANT and Bax $[105,106]$. It protects the cells against CD95 ligation [36], over expression of Bid [106], staurosporine [105] and oxidative stress induced cell death $[107,108]$. In overall the vMIA protein maintains the morphology of mitochondria without MMP $(\Delta \psi \mathrm{m})$ loss [109]. In in vitro studied, the overexpression of vMIA in cells lacking Bax results in mitochondrial alteration which indicates the Bax is not involved in vMIA mediated mitochondrial cell death. The exact mechanism of how vMIA works is not fully understood but it do protects the cells from downstream events of apoptosis but not upstream of mitochondrial by blocking Cyt $\mathrm{c}$ release, caspase 9 activation and ATP generation.

9. KHSV encoded K15 protein possess a special putative repeat at its $\mathrm{c}$ terminus region. The localization of k15 protein into mitochondria binds to pro apoptotic protein Nip3 and antiapoptotic protein Hax-1 with sequence similarity to Bcl-2 [110]. This makes the infected cells unable to undergo the process of apoptosis. Therefore k15 plays a key role in tumorigenesis and is usually expressed during latency in infection tumors [111].

10. The in vitro transient study carried upon two AEV virus encoded genes Vp3 (structural protein) and protein 2C (nonstructural) protein has revealed that both the proteins localizes to mitochondria. Vp3 induces Cas-3 mediated cell death pathway whereas $2 \mathrm{c}$ induces the release of cytochrome $c$ by loss of MMP $(\Delta \psi \mathrm{m})$ and ultimately activates downstream Cas 9 and Cas 3 leading to apoptosis $[112,113]$. The $2 c$ protein has been found highly conserved among the picornaviruses but the exact role played by $2 \mathrm{c}$ in viral replication is still not clearly understood.

11. The protein 7A encoded by SARS-Cov genome is a viral apoptosis inducing gene by inhabiting the host anti apoptotic gene Bcl-xL $[114,115]$. Further in vitro studies has shown NSP15 protein encoded by SARS virus has been unable to block apoptosis induced by staurosporin whereas it blocks apoptosis in a dose dependent manner upon overexpression of MAVS in cultured cells [116].

12. Viruses using the mitochondrial machinery to modulate the host interferon response (HCV virus reducing host betainterferon production through the RIG1 pathway):

The protein NS3/4A encoded by the genome of HCV usually persists in its host by effecting the interferon production involving RIG-I pathway $[117,118]$. The protein is a serine protease which cleaves MAVS at cys-508, which is located near its mitochondrial targeting domain. The protease activity makes MAVS inactivated by detaches MAVS from mitochondria as they are nonfunctional in free form. Further studies [119,120] have revealed that the NS3/4A can co-localize to mitochondria directly, however a mutation by arginine at cys-508 has shown can prevent the cleavage of MAVS from mitochondria [120]. Therefore this indicates that HCV hijacks the MAVS of the mitochondria to suppress the host immune response.

13. Cleavage of mitochondrial MAVS (mitochondrial anti-viral proteins) to paralyze the host immune response by GB virus. Similarly the GB virus B belonging to family Flaviviradie cleaves MAVS from mitochondria in a similar fashion as does by $\mathrm{HCV}$ viruses which weakens the host immune response be decreasing the interferon production [121]. However the mutation studies carried in the HCV has shown the importance of cysteine residue in cleaving the MAVS from mitochondria.

14. The GSIV fish virus serine/theroine kinase gene induces apoptotic cell death via p53 mediated up regulation of Bax and down regulation of $\mathrm{Bcl}-2$ which causes MMP $(\Delta \psi \mathrm{m})$ loss [122]. This loss of MMP $(\Delta \psi \mathrm{m})$ then mediates cell death signaling, which in turn results in an activation of the caspase mediated cell death pathways at the mid to late stage of viral replication.

15. The fish Betanodavirus non-structural protein B2 is a proapoptotic gene. The $\mathrm{B} 2$ protein results in mitochondria mediated necrotic cell death in grouper liver cells (GL-av). The transiently expressed B2 upregulates expression of the proapoptotic gene Bax and loss of MMP $(\Delta \psi \mathrm{m})$ but not cytochrome C-release $[123,124]$. Taken together, results suggest that $\mathrm{B} 2$ upregulates Bax and triggers mitochondria-mediated necrotic cell death independent of cytochrome $c$ release.

16. The sub major capsid protein, VP3 of aquatic birnavirus upregulates the proapoptotic protein Bad in fish and Mouse cells. The sub major capsid Vp3 induced up regulation of Bad expression alters mitochondrial function including MMP $(\Delta \psi \mathrm{m})$ loss and activation of initiator caspase 9 and caspase 3 $[125,126]$.

17. Viruses appropriating the host mitochondrial protein p32 to self-replicate (Rubella virus: The capsid protein encoded by the genome of Rubella virus hijacks the function of $\mathrm{p} 32$ mitochondrial matrix protein. Studies have shown that the capsid protein possess two clusters of arginine residues which are required for its interaction with P32 protein. The expression of the capsid protein alone in cell culture studies has shown to induce perinuclear clustering of mitochondria and the formation of electrondense intermitochondrial plaques, which are both observed in RV-infected cells [127]. Mutagenic studies in which recombinant virus encoded arginine to alanine mutation in the $\mathrm{p} 32$ binding region of capsid protein resulted in decreased mitochondrial clustering, indicating that interactions with this cellular protein are required for capsid-dependent reorganization of mitochondria and replicated to lower titers. Therefore disruption of stable interactions between capsid and p32 was found to be associated with decreased production of sub genomic RNA which in turn lowers virus replication and ultimately leads to less virus progeny [127].

\section{Use of molecular mimicry by viruses to invade mitochondria}

During the process of coevolution some viruses have evolved to encode proteins that mimic the activity of their host proteins to successfully complete their life cycle without the hindrance of host immune response. For example Mimivirus, a member of the newly created virus family Mimiviridae, encodes a eukaryotic mitochondria carrier protein (VMC-I) [128], this protein mimics the function of the host cell's mitochondrial carrier protein which controls the mitochondrial transport machinery in infected cells. Therefore taking control of host cells transport of ADP, dADP, TTP, dTTP and UTP in exchange for dATP across membrane, for energy production which virus uses for replication of its genome to produce new progeny [128]. In addition several other proteins encoded by the same virus (L359, L572, R776, R596, R740, R824 L81, R151, R900 and L908) with 
mitochondria localization signals, which suggest that mimivirus has evolved a strategy to take over the control of host energy production units (mitochondria) for its use to replicate [128].

\section{Viruses deplete the host mitochondrial DNA (mtDNA) to evade from the mitochondria evoked antiviral host responses}

Mitochondria play an important role in host cell survival. In addition to respiratory functions, plays a crucial role in cellular antiviral defenses including apoptosis and the type 1 interferon response. Therefore performing various other functions which make them absolutely indispensable to the cell, different viruses appear to have adopted the strategy of damaging the host cell mitochondrial DNA to take control of the whole cell. Thus the ability of viruses to interfere with Herpes simplex virus (HSV) causes both productive and latent infections in its human host. The HSV-1UL12 gene encodes two distinct proteins: UL12 and UL12.5. The UL12 is an alkaline nuclease, and the UL12.5 is an N terminally truncated 500 -aa polypeptide that lacks the first 126 residues of UL12 [129]. Mostly UL12 is known to play a crucial role in viral genome replication and processing [130]. UL12.5 does not accumulate in nucleus but also nuclease and strand-exchange activities [131]. UL12.5 localizes predominantly to mitochondria, where it triggers massive degradation of mitochondrial DNA early during HSV replication [132]. In addition to that UL12.5 has been found to acts directly within the mitochondrial matrix to degrade mitochondrial DNA by its nuclease activities [133].

In case of $\mathrm{HCV}$ infection, the generation of reactive oxygen species causes damage to host mitochondrial DNA. The Zta protein of EBV interferes with the mitochondrial single strand DNA binding protein to reduce the mitochondrial DNA replication and increase in viral DNA replication [134]. Interestingly, depletion of mtDNA has also been observed in HIV/HCV coinfected humans. However, the fully understood biological importance of mitochondrial DNA damage during the whole infection cycle still remains confusing.

\section{Conclusion}

Mitochondria are now known as being vital in the regulation of cell survival and death. Therefore, an ever-expanding number of signal-transducing molecules, like viral effectors have been identified to act on mitochondria and to influence MMP $(\Delta \psi \mathrm{m})$. Recent studies have shown that many viruses encode protein that are targeted into mitochondria and control a number of functions, including apoptosis, cell growth, ionic haemostasis and signalling pathways. Many virus genomes (HIV, HCV, KHSV and CMV) encode various proteins in their hosts having both pro and anti-apoptotic activity and activate them depending on their need. This highlights the mechanisms by which these viruses regulate the dynamic balance between the anti and pro- apoptotic Bcl-2 family proteins to increase their chances of survival inside the host cell. The overall data summarized in the review have shown that mitochondria act as a one of the cherished organelle for invading viruses and many virus encoded mitochondrial targeted proteins play a significant role in the pathogenesis of the disease they cause. Therefore exploring the exact roles of viral genes as well as whole viruses in apoptosis at molecular level could lead to the discovery of novel therapeutic strategies and pathogenic insights into different viral diseases. Essential and important questions, however still remains unanswered concerning the molecular mechanisms of MMP $(\Delta \psi \mathrm{m})$ induced by viral proteins/viruses. Therefore answering these queries may result in identification of key MMP $(\Delta \psi \mathrm{m})$ regulatory process involved in MMP $(\Delta \psi \mathrm{m})$ loss and viral host protein protein interactions. The prevention and treatment of viral infection is quite challenging task but studying virus/host/protein interactions at molecular level will help in providing various opportunities for both identifying as well as rationally designing new cytotoxic or cytoprotective drugs.

\section{References}

1. Bossy-Wetzel E, Barsoum MJ, Godzik A, Schwarzenbacher R, Lipton SA (2003) Mitochondrial fission in apoptosis, neurodegeneration and aging. Curr Opin Cell Biol 15:706-716.

2. Wallace DC (2005) A mitochondrial paradigm of metabolic and degenerative diseases, aging and cancer: A dawn for evolutionary medicine. Annu Rev Genet 39: 359-407.

3. Chan DC (2006) Mitochondria: Dynamic organelles in disease, aging and development. Cell 125: 1241-1252.

4. Hackenbrock CR (1966) Ultrastructural bases for metabolically linked mechanical activity in mitochondria. I. Reversible ultrastructural changes with change in metabolic steady state in isolated liver mitochondria. J Cell Biol 30: 269-297.

5. Mannella CA, Pfeiffer DR, Bradshaw PC, Moraru II, Slepchenko B, et al. (2001) Topology of the mitochondrial inner membrane: Dynamics and bioenergetic implications. IUBMB Life 52: 93-100.

6. McBride HM, Neuspiel M, Wasiak S (2006) Mitochondria: More than just a powerhouse. Curr Biol 16: R551-560.

7. Kroemer G, Galluzzi L, Brenner C (2007) Mitochondrial membrane permeabilization in cell death. Physiol Rev 87: 99-163.

8. Mandal S, Guptan P, Owusu-Ansah E, Banerjee U (2005) Mitochondria regulation of cell cycle progression during development as revealed by the tenured mutation in drosophila. Dev Cell 9: 843-854.

9. Honda S, Hirose S (2003) Stage-specific enhanced expression of mitochondria fusion and fission factors during spermatogenesis in rat testis. Biochemical and Biophysical Research Communications. 311:424-432.

10. Bakeeva LE, Chentsov YS, Skulachev VP (1983) Intermitochondrial contacts in myocardiocytes. J Mol Cell Cardiol 15: 413-420.

11. Bossy-Wetzel E, Barsoum MJ, Godzik A, Schwarzenbacher R, Lipton SA (2003) Mitochondrial fission in apoptosis, neurodegeneration and aging. Curr. Opin Cell Biol. 15:706-716.

12. Martin LJ (2006) Mitochondriopathy in Parkinson disease and amyotrophic lateral sclerosis. J Neuropathol Exp Neurol 65: 1103-1110.

13. Van Den Eeden SK, Tanner CM, Bernstein AL, Fross RD, Leimpeter A, et al. (2003) Incidence of Parkinson's disease: Variation by age, gender and race/ ethnicity. Am J Epidemiol 157:1015-1022.

14. Seth RB, Sun L, Chen ZJ (2006) Antiviral innate immunity pathways. Cell Res 16: 141-147.

15. Vanlandschoot P, Leroux-Roels G (2003) Viral apoptotic mimicry: An immune evasion strategy developed by the hepatitis B virus? Trends Immunol 24: 144147.

16. Papa S (1996) Mitochondrial oxidative phosphorylation changes in the life span. Molecular aspects and physiopathological implications. Biochim. Biophys. Acta 1276: 87-105.

17. Liu J, Chen I, Kwang J (2005) Characterization of a previously unidentified vira protein in porcine circovirus type 2-infected cells and its role in virus-induced apoptosis. J Virol 79: 8262-8274.

18. Ashkenazi A, Dixit VM (1998) Death receptors: Signaling and modulation. Science 281:1305-1308.

19. Münz C (2007) Viral evasion of autophagy. Cell Host Microbe 1: 9-11.

20. Benedict CA, Norris PS, Ware CF (2002) To kill or be killed: Viral evasion of apoptosis. Nat Immunol 3: 1013-1018.

21. Pearce AF, Lyles DS (2009) Vesicular stomatitis virus induces apoptosis primarily through Bak rather than Bax by inactivating Mcl-1 and Bcl-XL. J Viro 83: $9102-9112$

22. Mao H, Tu W, Qin G, Law HK, Sia SF, et al. (2009) Influenza virus directly infects human natural killer cells and induces cell apoptosis. J Virol 83: 9215-9222.

23. Orvedahl A, Levine B (2009) Eating the enemy within: Autophagy in infectious diseases. Cell Death Differ 16: 57-69. 
24. Wong J, Zhang J, Si X, Gao G, Mao I, et al. (2008) Autophagosome supports coxsackie virus B3 replication in host cells. J Virol 82: 9143-9153.

25. Lee YR, Lei HY, Liu MT, Wang JR, Chen SH, et al. (2008) Autophagic machinery activated by dengue virus enhances virus replication. Virology 374: 240-248.

26. Levine AJ (1997) The cellular gatekeeper for growth and division. Cell 1997 88: 323-331.

27. Rao L, White $E$ (1997) Bcl-2 and the ICE family of apoptotic regulators: making a connection. Curr Opin Genet Dev 7: 52-58.

28. Reshi, Mohammad Latif, Yi-Che Su, Jiann-Ruey Hong (2014) RNA viruses: ROS-mediated cell death. Int J Cell Biol 2014: 467-452

29. Clem RJ, Duckett CS (1997) The iap genes: Unique arbitrators of cell death Trends Cell Biol 7: 337-339.

30. Nagata S (1997) Apoptosis by death factor. Cell 88: 355-365.

31. Reshi L, Wu JL, Wang HV, Hong JR (2016) Aquatic viruses induce host cell death pathways and its application. Virus Res 211: 133-144.

32. White $E$ (1996) Life, death and the pursuit of apoptosis. Genes Dev.10: 1-15.

33. Chen L, Willis SN, Wei A, Smith BJ, Fletcher JI, et al. (2005) Differential targeting of prosurvival $\mathrm{Bcl}-2$ proteins by their $\mathrm{BH} 3$-only ligands allows complementary apoptotic function. Mol Cell 2005; 17: 393-403.

34. Letai $\mathrm{A}$ (2005) Pharmacological manipulation of $\mathrm{Bcl}-2$ family members to control cell death. J Clin Invest 115: 2648-2655.

35. Scorrano L, Oakes SA, Opferman JT, Cheng EH, Sorcinelli MD, et al. (2003) $\mathrm{BAX}$ and BAK regulation of endoplasmic reticulum $\mathrm{Ca}^{2+}$ : A control point for apoptosis. Science 300: 135-139.

36. Kokoszka JE, Waymire KG, Levy SE, Sligh JE, Cai J, et al. (2004) The ADP/ ATP translocator is not essential for the mitochondrial permeability transition pore. Nature 427: 461-465.

37. Kroemer G, Galluzzi L, Brenner C (2007) Mitochondrial membrane permeabilization in cell death. Physiol Rev 87: 99-163.

38. Galluzzi L, Kroemer G (2007) Mitochondrial apoptosis without VDAC. Nat Cell Biol 9: 487-489.

39. Gougeon ML (2003) Apoptosis as an HIV strategy to escape immune attack. Nat Rev Immunol 3:392-404.

40. D’Agostino DM, Silic-Benussi M, Hiraragi H, Lairmore MD, Ciminale V (2005) The human T-cell leukemia virus type 1 p13ll protein: Effects on mitochondrial function and cell growth. Cell Death Differ 12: 905-915.

41. Yoshida M (2001) Multiple viral strategies of HTLV-1 for dysregulation of cell growth control. Annu Rev Immunol 19: 475-496.

42. Gibbs JS, Malide D, Hornung F, Bennink JR, Yewdell JW (2003) The influenza A virus PB1-F2 protein targets the inner mitochondrial membrane via a predicted basic amphipathic helix that disrupts mitochondrial function. J Virol 77: 72147224.

43. Perfettini JL, Roumier T, Castedo M, Larochette N, Boya P, et al. (2004) NFkappaB and p53 are the dominant apoptosis-inducing transcription factors elicited by the HIV-1 envelope. J Exp Med 199: 629-640.

44. Castedo M, Ferri KF, Blanco J, Roumier T, Larochette N, et al. (2001) Human immunodeficiency virus 1 envelope glycoprotein complex-induced apoptosis involves mammalian target of rapamycin/FKBP12-rapamycin-associated protein-mediated p53 phosphorylation. J Exp Med 194: 1097-1110.

45. Hart LS, Ornelles D, Koumenis C (2007) The adenoviral E4orf6 protein induces atypical apoptosis in response to DNA damage. J Biol Chem 282: 6061-6067.

46. Shimazu T, Degenhardt K, Nur EKA, Zhang J, Yoshida T, et al. (2007) NBK/ BIK antagonizes MCL- 1 and BCL-XL and activates BAK-mediated apoptosis in response to protein synthesis inhibition. Genes Dev 21: 929-941.

47. Nie Z, Phenix BN, Lum JJ, Alam A, Lynch DH, et al. (2002) HIV-1 protease processes procaspase 8 to cause mitochondrial release of cytochrome c, caspase cleavage and nuclear fragmentation. Cell Death Differ 9: 1172-1184.

48. Cuconati A, White E (2002) Viral homologs of BCL-2: Role of apoptosis in the regulation of virus infection. Genes Dev 16: 2465-2478.

49. Tan YX, Tan TH, Lee MJ, Tham PY, Gunalan V, et al. (2007) Induction of apoptosis by the severe acute respiratory syndrome coronavirus 7 a protein is dependent on its interaction with the Bcl-XL protein . J Virol 81: 6346-6355.
50. Goldmacher VS, Bartle LM, Skaletskaya A, Dionne CA, Kedersha NL, et al. (1999) A cytomegalovirus-encoded mitochondria-localized inhibitor of apoptosis structurally unrelated to Bcl-2. Proc Natl Acad Sci USA 96: 12536-12541.

51. Chiou SK, Tseng CC, Rao L, White E (1994) Functional complementation of the adenovirus E1B 19-kilodalton protein with Bcl-2 in the inhibition of apoptosis in infected cells. J Virol 68: 6553-6566

52. Marzo I (1998) Bax and adenine nucleotide translocator cooperate in the mitochondrial control of apoptosis. Science 281: 2027-2031.

53. Crompton $M(1999)$ The mitochondrial permeability transition pore and its role in cell death. Biochem. J 341: 233-249.

54. Brenner C (2000) Bcl-2 and Bax regulate the channel activity of the mitochondrial adenine nucleotide translocator. Oncogene 19: 329-336.

55. Goldmacher VS (1999) A cytomegalovirus-encoded mitochondria-localized inhibitor of apoptosis structurally unrelated to Bcl-2. Proc Natl Acad Sci U S A 96: 12536-12541.

56. Jacotot $E$ (2000) The HIV-1 viral protein R induces apoptosis via a direct effect on the mitochondrial permeability transition pore. J Exp Med 191: 33-45.

57. Eskes R (1998) Bax-induced cytochrome c release from mitochondria is independent of the permeability transition pore but highly dependent on $\mathrm{Mg}^{2+}$ ions. J Cell Biol. 143: 217-224.

58. Eskes R, Desagher S, Antonsson B, Martinou JC (2000) Bid induces the oligomerization and insertion of Bax into the outer mitochondrial membrane. Mol Cell Biol 20: 929-935.

59. Vander Heiden MG, Thompson CB (1999) Bcl-2 proteins: Inhibitors of apoptosis or regulators of mitochondrial homeostasis? Nature Cell Biol 1: E209-E216.

60. Van der Heiden M, Chandel NS, Schumacker PT, Thompson CB (1999) $\mathrm{Bcl}-\mathrm{XL}$ prevents cell death following growth factor withdrawal by facilitating mitochondrial ATP/ADP exchange. Mol Cell 3: 159-167.

61. Maniatis T, Falvo JV, Kim TH, Kim TK, Lin CH, et al. (1998) Structure and function of the interferon-beta enhanceosome. Cold Spring Harb Symp Quant Biol 63: 609-620.

62. Seth RB, Sun L, Ea CK, Chen ZJ (2005) Identification and characterization of MAVS, a mitochondrial antiviral signaling protein that activates NF-kappa B and IRF 3. Cell 122: 669-682.

63. Xu LG, Wang YY, Han KJ, Li LY, Zhai Z, et al. (2005) VISA is an adapter protein required for virus-triggered IFN-beta signaling. Mol Cell 19: 727-740.

64. Kawai T, Takahashi K, Sato S, Coban C, Kumar H, et al. (2005) IPS-1, an adaptor triggering RIG-I- and Mda5-mediated type I interferon induction. Nat Immunol 6: 981-988.

65. Meylan E, Curran J, Hofmann K, Moradpour D, Binder M, et al. (2005) Cardif is an adaptor protein in the RIG-I antiviral pathway and is targeted by hepatitis C virus. Nature 437: 1167-1172.

66. Sun Q, Sun L, Liu HH, Chen X, Seth RB, et al. (2006) The specific and essential role of MAVS in antiviral innate immune responses. Immunity 24: 633-642.

67. Breiman A, Grandvaux N, Lin R, Ottone C, Akira S, et al. (2005) Inhibition of RIG-I-dependent signaling to the interferon pathway during hepatitis $C$ virus expression and restoration of signaling by IKKepsilon. J Virol 79: 3969-3978.

68. Hay S, Kannourakis G (2002) A time to kill: Viral manipulation of the cell death program. J Gen Virol 83: 1547-1564.

69. Balachandran S, Roberts PC, Kipperman T, Bhalla KN, Compans RW, et al. (2000) Alpha/beta interferons potentiate virus-induced apoptosis through activation of the FADD/ caspase-8 death signaling pathway. J Virol 74:15131523.

70. Gale M Jr (2003) Effector genes of interferon action against hepatitis C virus Hepatology 37: 975-978.

71. Garcia MA, Guerra S, Gil JS, Jimenez V, Esteban M, et al. (2002) Antiapoptotic and oncogenic properties of the dsRNA-binding protein of vaccinia virus, E3L. Oncogene 21: 8379-8387.

72. Hawkins CJ, Uren AG, Hacker G, Medcalf RL, Vaux RL (1996) Inhibition of interleukin 1 beta-converting enzyme-mediated apoptosis of mammalian cells by baculovirus IAP. PNAS 93: 13786-13790.

73. Nogal ML, Buitrago de GG, Rodriguez C, Cubelos B, Carrascosa AL, et al (2001) African swine fever virus IAP homologue inhibits caspase activation and promotes cell survival in mammalian cells. J Virol 75: 2535-2543. 
74. Blondel B, Colbere-Garapin F, Couderc T, Wirotius A, Guivel-Benhassine F (2005) Poliovirus, pathogenesis of poliomyelitis, and apoptosis. Curr Top Microbiol Immunol 289: 25-56

75. Madan V, Castelló A, Carrasco L (2008) Viroporins from RNA viruses induce caspase-dependent apoptosis. Cell Microbiol 10: 437-451.

76. Nudson WA, Rovnak J, Buechner M, Quackenbush SL (2003) Walleye dermal sarcoma virus Orf $C$ is targeted to the mitochondria. J Gen Virol 84: 375-381.

77. LaPierre LA, Casey JW, Holzschu DL (1998) Walleye retroviruses associated with skin tumors and hyperplasias encode cyclin D homologs. J Virol 72: 87658771.

78. Doorbar J, Ely S, Sterling J, McLean C, Crawford L (1991) Specific interaction between HPV-16 E1-E4 and cytokeratins results in collapse of the epithelial cell intermediate filament network. Nature 352: 824-827.

79. Scheffner M, Werness BA, Huibregtse JM, Levine AJ, Howley PM (1990) The E6 oncoprotein encoded by human papillomavirus types 16 and 18 promotes the degradation of p53. Cell 63: 1129-1136.

80. Brown J, Higo H, McKalip A, Herman B (1997) Human papillomavirus (HPV) 16 E6 sensitizes cells to atractyloside-induced apoptosis: Role of p53, ICE-like proteases and the mitochondrial permeability transition. J Cell Biochem 66 245-255.

81. Vikhanskaya F, Falugi C, Valente P, Russo P (2002) Human papillomavirus type 16 E6-enhanced susceptibility to apoptosis induced by TNF in A2780 human ovarian cancer cell line. Int J Cancer 97 732-739.

82. Liu Y, McKalip A, Herman B (2000) Human papillomavirus type 16 E6 and HPV-16 E6/ E7 sensitize human keratinocytes to apoptosis induced by chemotherapeutic agents: roles of p53 and caspase activation. J. Cell. Biochem 78: 334-349.

83. Giannini C, Bréchot C (2003) Hepatitis C virus biology. Cell Death Differ 10 S27-38.

84. Machida K, Tsukiyama-Kohara K, Seike E, Tone S, Shibasaki F, et al. (2001) Inhibition of cytochrome $\mathrm{c}$ release in Fas-mediated signaling pathway in transgenic mice induced to express hepatitis $\mathrm{C}$ viral proteins. J Biol Chem 276 : 12140-12146

85. Licata JM, Harty RN (2003) Rhabdoviruses and apoptosis. Int Rev Immunol 22: $451-476$

86. Gadaleta P, Perfetti X, Mersich S, Coulombié F (2005) Early activation of the mitochondrial apoptotic pathway in vesicular stomatitis virus-infected cells. Virus Res 109: 65-69.

87. Gadaleta P, Vacotto M, Coulombié F (2002) Vesicular stomatitis virus induces apoptosis at early stages in the viral cycle and does not depend on virus replication. Virus Res 86: 87-92.

88. Gaddy DF, Lyles DS (2005) Vesicular stomatitis viruses expressing wild-type or mutant $\mathrm{M}$ proteins activate apoptosis through distinct pathways. J Virol 79: 4170-4179.

89. Das SC, Pattnaik AK (2004) Phosphorylation of vesicular stomatitis virus phosphoprotein $\mathrm{P}$ is indispensable for virus growth. J Virol 78: 6420-6430.

90. Chen W, Calvo PA, Malide D, Gibbs J, Schubert U, et al. (2001)A novel influenza A virus mitochondrial protein that induces cell death. Nat Med 7: 1306-1312.

91. Bruns K, Studtrucker N, Sharma A, Fossen T, Mitzner D, et al. (2007) Structura characterization and oligomerization of PB1-F2, a proapoptotic influenza A virus protein. J Biol Chem 282: 353-363.

92. Gibbs JS, Malide D, Hornung F, Bennink JR, Yewdell JW (2003) The influenza A virus PB1-F2 protein targets the inner mitochondrial membrane via a predicted basic amphipathic helix that disrupts mitochondrial function. J Virol 77:7214-7224.

93. Zamarin D, Garcia-Sastre A, Xiao X, Wang R, Palese P (2005) Influenza virus PB1-F2 protein induces cell death through mitochondrial ANT3 and VDAC1. PLoS Pathog 1: e4.

94. Kim CM, Koike K, Saito I, Miyamura T, Jay G (1991) HBx gene of hepatitis B virus induces liver cancer in transgenic mice. Nature 351: 317-320.

95. Wang Y, Lau SH, Sham JST, Wu MC,Wang T, et al. (2004) Characterization of HBV integrants in 14 hepatocellular carcinomas: Association of truncated $\mathrm{X}$ gene and hepatocellular carcinogenesis. Oncogene 23: 142-148.

96. Su F, Schneider RJ (1997) Hepatitis B virus HBx protein sensitizes cells to apoptotic killing by tumor necrosis factor alpha. PNAS 94: 8744-8749.
97. Takada S, Shirakata Y, Kaneniwa N, Koike K (1999) Association of hepatitis $B$ virus $X$ protein with mitochondria causes mitochondrial aggregation at the nuclear periphery, leading to cell death. Oncogene 18: 6965-6973.

98. Henkler F, Hoare J, Waseem N, Goldin RD, McGarvey MJ, et al (2001) Intracellular localization of the hepatitis B virus HBx protein. J Gen Virol 82: 871-882.

99. Rahmani Z, Huh KW, Lasher R, Siddiqui A (2000) Hepatitis B virus X protein colocalizes to mitochondria with a human voltage-dependent anion channel, HVDAC3, and alters its transmembrane potential. J Virol 74: 2840-2846.

100. Tanaka Y, Kanai F, Kawakami T, Tateishi K, ljichi H, et al. (2004) Omata, Interaction of the hepatitis $B$ virus $X$ protein $(\mathrm{HBx})$ with heat shock protein 60 enhances HBx-mediated apoptosis. Biochem Biophys Res Commun 318 : 461-469.

101. Krahenbuhl S, Stucki J, Reichen J (1989) Mitochondrial-function in carbon tetrachloride-induced cirrhosis in the rat- qualitative and quantitative defects Biochem Pharmacol 38: 1583-1588.

102. Goldmacher VS, Bartle LM, Skaletskaya A, Dionne CA, Kedersha NL, et al. (1999) A cytomegalovirus-encoded mitochondria-localized inhibitor of apoptosis structurally unrelated to bcl-2. Proc Natl Acad Sci U S A 96:12536-12541.

103. Poncet D, Larochette N, Pauleau AL, Boya P, Jalil AA, et al. (2004) An antiapoptotic viral protein that recruits Bax to mitochondria. J Biol Chem 279 : 22605-22614

104. Arnoult D, Bartle LM, Skaletskaya A, Poncet D, Zamzami N, et al. (2004) Cytomegalovirus cell death suppressor vMIA blocks bax- but not bak-mediated apoptosis by binding and sequestering bax at mitochondria. Proc Natl Acad Sci USA 101:7988-7993.

105. Vieira HL, Belzacq AS, Haouzi D, Bernassola F, Cohen I, et al. (2001) The adenine nucleotide translocator: A target of nitric oxide, peroxynitrite, and 4-hydroxynonenal. Oncogene 20:4305-4316.

106. Boya P, Morales MC, Gonzalez-Polo RA, Andreau K, Gourdier I, et al (2003) The chemopreventive agent N-(4-hydroxyphenyl)retinamide induces apoptosis through a mitochondrial pathway regulated by proteins from the bcl2 family. Oncogene 22: 6220-6230.

107. McCormick AL, Smith VL, Chow D, Mocarski ES (2003) Disruption of mitochondrial networks by the human cytomegalovirus UL37 gene product viral mitochondrion-localized inhibitor of apoptosis. J Virol 77:631-641.

108. Suzuki Y, Demoliere C, Kitamura D, Takeshita H, Deuschle U, et al. (1997) HAX-1, a novel intracellular protein, localized on mitochondria, directly associates with HS1, a substrate of Src family tyrosine kinases. Open J Immunol 158: 2736-2744.

109. Sharp TV, Wang HW, Koumi A, Hollyman D, Endo Y, et al. (2002) K15 protein of Kaposi's sarcoma-associated herpesvirus is latently expressed and binds to HAX-1, a protein with anti-apoptotic function. J Virol 76: 802-816.

110. Moore PS, Chang Y (2003) Kaposi's sarcoma-associated herpes virus immunoevasion and tumorigenesis: Two sides of the same coin. Annu Rev Microbiol 57: 609-639.

111. Liu J, Wei T, Kwang J (2002) Avian encephalomyelitis virus induces apoptosis via major structural protein VP3. Virology 300: 39-49.

112. Liu J, Wei T, Kwang J (2004) Avian encephalomyelitis virus non-structural protein $2 \mathrm{C}$ induces apoptosis by activating cytochrome c/caspase- 9 pathway. Virology 318:169-182.

113. Tan YX, Tan THP, Lee MJR., Tham PY, Gunalan V, et al. (2007) Induction of apoptosis by the severe acute respiratory syndrome coronavirus 7a protein is dependent on its interaction with the Bcl-XL protein. J Virol 81: 6346-6355.

114. Schaecher SR, Touchette E, Schriewer J, Buller RM, Pekosz A (2007) Severe acute respiratory syndrome coronavirus gene 7 products contribute to virusinduced apoptosis. J Virol 81: 11054-11068.

115. Lei Y, Moore CB, Liesman RM, O'Connor BP, Bergstralh DT, et al. (2009) MAVSmediated apoptosis and its inhibition by viral proteins. PLoS ONE 4: e5466.

116. Breiman A, Grandvaux N, Lin R, Ottone C, Akira S, et al. (2005) Inhibition of RIG-I-dependent signaling to the interferon pathway during hepatitis $C$ virus expression and restoration of signaling by IKKepsilon. J Virol 79: 3969-3978.

117. Foy E, Li K, Sumpter R, Jr Loo YM, Johnson CL, Wang C, et al. (2005) Contro of antiviral defenses through hepatitis $C$ virus disruption of retinoic acidinducible gene-I signaling. Proc Natl Acad Sci USA 102:2986-2991

118. Foy E, Li K, Wang C, Sumpter R, Jr Ikeda M, et al. (2003) Regulation of interferon regulatory factor- 3 by the hepatitis $\mathrm{C}$ virus serine protease. Science 300:1145-1148. 
119. Meylan E, Curran J, Hofmann K, Moradpour D, Binder M, et al. (2005) Cardif is an adaptor protein in the RIG-I antiviral pathway and is targeted by hepatitis C virus. Nature 437: 1167-1172.

120.Li XD, Sun L, Seth RB, Pineda G, Chen ZJ (2005) Hepatitis C virus protease NS3/4A cleaves mitochondrial antiviral signaling protein off the mitochondria to evade innate immunity. Proc Natl Acad Sci USA 102:17717-17722.

121. Chen Z, Benureau Y, Rijnbrand R, Yi J, Wang T, et al. (2007) GB virus $B$ disrupts RIG-I signaling by NS3/4A-mediated cleavage of the adaptor protein MAVS. J Virol 81: 964-976.

122. Reshi L, Wu HC, Wu JL, Wang HV, et al. (2016) GSIV serine/threonine kinase can induce apoptotic cell death via p53 and pro-apoptotic gene Bax upregulation in fish cells. Apoptosis 21: 443-458.

123. Su Yu-Chin, Jen-Leih Wu, Jiann-Ruey Hong (2009) Betanodavirus nonstructural protein B2: A novel necrotic death factor that induces mitochondriamediated cell death in fish cells. Virology 385: 143-154.

124. Hironobu M (2016) Inefficient viral replication of bovine leukemia virus induced by spontaneous deletion mutation in the G4 gene. J Gen Virol 97: 2753-2762.

125. Chien-Li C (2010) Aquatic birnavirus capsid protein, VP3, induces apoptosis via the Bad-mediated mitochondria pathway in fish and mouse cells. Apoptosis 15: 653-668.

126. Martin DB (2005) Interactions between rubella virus capsid and host protein p32 are important for virus replication. J Virol 79: 10807-10820.
127. Monn'e M, Robinson AJ, Boes C, Harbour ME, Fearnley IM, et al. (2007) The mimivirus genome encodes a mitochondrial carrier that transports dATP and dTTP. J Virol 81: 3181-3186.

128. Bronstein JC, Weller SK, Weber PC (1997) The product of the UL12.5 gene of herpes simplex virus type 1 is a capsid-associated nuclease. J Virol 71: 3039-3047

129. Martinez R, Shao L, Bronstein JC, Weber PC, Weller SK (1996) The product of a 1.9-kb mRNA which overlaps the HSV-1 alkaline nuclease gene (UL12) cannot relieve the growth defects of a null mutant. Virology 215: 152-164.

130. Reuven NB, Antoku S, Weller SK (2004) The UL12.5 gene product of herpes simplex virus type 1 exhibits nuclease and strand exchange activities but does not localize to the nucleus. J Virol 78:4599-4608.

131. Saffran HA, Pare JM, Corcoran JA, Weller SK, Smiley JR (2007) Herpes simplex virus eliminates host mitochondrial DNA. EMBO Rep 8: 188-193.

132. Corcoran JA, Saffran HA, Duguay BA, Smiley JR (2009) Herpes simplex virus UL12.5 targets mitochondria through a mitochondrial localization sequence proximal to the $\mathrm{N}$ terminus. 83: 2601-2610.

133. Wiedmer PW, Zhou J (2008) Epstein-Barr virus immediate-early protein Zta co-opts mitochondrial single stranded DNA binding protein to promote viral and inhibit mitochondrial DNA replication. J Virol 82: 4647- 4655.

134. Mendoza de C, Martin-Carbonero L, Barreiro P (2007) Mitochondrial DNA depletion in HIV-infected patients with chronic hepatitis $\mathrm{C}$ and effect of pegylated interferon plus ribavirin therapy. AIDS 21: 583-588.
This article was originally published in a special issue, Molecules involved in cell signaling pathways handled by Editor(s). Dr. Masood Alam Khan, Al-Qassim University, Saudi Arabia 